\title{
Opinion on the Main Contradictory Relationship and Features in the Modernization Development of Wushu
}

\author{
Xue Yu, Zhang Xu \\ Department of Physical Education and Research, Northwestern University \\ Shaanxi Xi'an, China 710127
}

\begin{abstract}
This paper carried out the thorough and detailed analysis for the main contradictory relationship and characteristics in the modernization development of Wushu to elaborate its important significance in the scientific development of Wushu. Meanwhile, this paper pointed out that the primary contradictory relationship of modernization development of Wushu included the contradiction between nationality and internationality, contradiction between tradition and modernity and contradiction between cultural nature and physical nature; the main features include dynamization and relativization, socialization and internationalization, scientization and informationization, diversification and humanization; in order to provide theoretical references for the development of Wushu modernization.
\end{abstract}

Keywords-Wushu; modernization; main contradiction; features

\section{INTRODUCTION}

Wushu is a sport, but it is higher than sport. As a sport, Wushu has its own particularity, which determines the modernization development of Wushu and it is also special, different from modernization of other sports. Such particularity of Wushu modernization is closely related to the different problems and contradictions appearing in the modernization development of Wushu, and it can be said that the particularity of Wushu modernization directly causes the occurrence of different contradictions in the modernization development of Wushu, but also affects and restricts the whole future development of the Wushu [1]. So identifying the main particularity of Wushu modernization, analyzing as well as the main contradictory relationship and its main features in the modernization development of Wushu can better promote the modernization development of Wushu, which is greatly significant for the future development of Wushu.

\section{MAIN CONTRADICTORY RELATIONSHIP OF THE MODERNIZATION DEVELOPMENT OF WUSHU}

The contradictory relationships of the modernization development of Wushu are mainly embodied in the following aspects:

Firstly, the contradiction between nationality and internationality;
In the development of modernization development of Wushu, it must face the contradictory relationship between nationality and internationalization. In essence, nationality and internationality can be unified, and this contradictory relationship can be transformed. "What belongs to nationality shall belong to the world". It is a good expression to the dialectical relationship between nationality and internationality.

Wushu modernization is not only to carry out the thorough transformation for it, just transform and remove the aspects which are not accepted by the modern society or opposite to the modern society, namely making it meet the development requirements of the current society at the premise of maintaining its nationality, integrating with social harmony, mutually promoting. Therefore, keep the nationality of Wushu itself to the top position in the modernization development of Wushu, always maintain national characteristics of Wushu in order to better introduce Chinese Wushu to the world, promote the internationalization development of it, and let it shine in the sports arena of the world with the unique national glory bloom.

Secondly, contradiction between tradition and modernity;

The contradiction between tradition and modernity is the most important contradiction relationship in the modernization development of Wushu. This kind of contradictory relationship is mainly embodied to be relationship between inheritance and innovation of Wushu, between inheritance and criticism of Wushu in the modernization development practice of Wushu. The modernization development of Wushu should not only inherit the essence of traditional Wushu, but also be innovative, and it should continuously innovate and develop whether or not in the form of motion, in the technical field, as well as in cultural connotation, development concept aspects, to enrich the value function of Wushu in modern society [2]

In Word-Ocean Dictionary, "tradition" is explained as: "social habit force handed down in the history, exists in the system, ideology, culture, morality and other fields... and tradition is the historical development succession performance." Although there are a lot of various explanations for "modernity" in the academic circle, its connotation is relatively stable, relatively clear: from the point of view of sociology, modernity marks accumulation and filling of nontraditional factors in the process of modernization (Parsons), is the transition of whole social culture system; from the 
perspective of history, modernity marks fracture and continuity to be unified, and it is the fracture in the continuity; from the perspective of psychology, modernity is experience and identity of modern people for the modern variation (in terms of time); from the perspective of philosophy, modernity is complementary variation and structure of subject and object (mutual mapping and acceptance) in the modern space-time. In addition, Jean-Francois Lyotard's Inhuman-Time Ramble explores the connotation of "modernity" from the perspective of natural ontology in his book, and holds that modernity is always confined to mankind and its society. Modernity refers to a new social order different from the past. It is a polymer of power, knowledge and social practice emphasizing innovation, change and progress.

It shows that the tradition and modernity are two different relative aspects, but the two can mutually merge, transform and promote each other at the same space time. The relationship between tradition and modernity is a relationship that promotes each other and restricts each other. It is also the relationship between criticism and inheritance, between inheritance and innovation. In order to realize the modernity of things, it must abandon the bad factors in tradition and get rid of the shackles of tradition [3]. At the same time, it should inherit the good things and create new aspects of things constantly. In the long course of social development, the emergence of any period is the continuation of the last period, and it is also the development of the last period. In the course of its modernization development, Chinese Wushu should make clear the relationship between tradition and modernity, grasp the main contradiction between the two of them, and transform each other at the same space time, and merge and unify with each other.

Thirdly, the contradiction between cultural nature and physical nature;

In the modernization development of Wushu, the similarities and differences between modern sports and Wushu are major obstacles to the modernization process. Physical properties of Wushu match with modern sports, but Wushu does not only have physical properties, also have profound cultural properties, and features of such properties that cause great difficulties for the modernization development of Chinese Wushu. It is extremely difficult to evaluate the modernization of Wushu. How can the sports properties and cultural properties of Wushu in the process of modernization be balanced? It will be one of the core issues in the modernization development of Wushu.

As SHI Yongxin, the abbot of Shaolin Temple, said, "Chinese Wushu has become a cross-country, cross-nation and even cross-faith cultural phenomenon, and has formed a Chinese Wushu culture circle in the world." In fact, Chinese Wushu has been separated from the state of simply using fists and feet, developed into a unique folk culture and played a unique cultural function." Thus, the culture of Wushu in modern society is especially prominent, playing an essential function itself, and showing the unique charm of oriental martial arts. This kind of cultural nature prominence is just the challenge of the physical nature of Wushu, which is also determined by the particularity of the modernization development of Chinese Wushu.

To a certain extent, the cultural nature and physical nature of Wushu embodies the contradiction between diversification and its uniqueness in the development of Wushu. In today's society, diversification is the general trend of sports development, but Wushu culture is relatively unique, how can this contradiction be balanced? In fact, the inheritance and development of current Wushu culture is based on the physical development of Wushu, and therefore, the modernization of Wushu culture should go forward with modern physical development of Wushu at the same time in the modernization development of Wushu, focusing on the characteristic of Wushu culture, which cannot be treated separately, and the cultural and physical nature of Wushu should be combined, which include the Wushu culture into the process of Wushu modernization development.

\section{MAIN FEATURES OF MODERNIZATION DEVELOPMENT OF WUSHU}

Feature is the extremely distinctive symbol or sign of something distinguished from something else. The features of the modernization development of Wushu mainly refer to the features of Wushu in modern society, and such feature is mainly different from symbol or sign of Wushu in the traditional society (here "traditional society Wushu" mainly refers to the traditional Wushu after the Opium War in 1840). Analysis of main features of the modernization development of Wushu is significant for the modernization development of Wushu, which contributes to scientifically and reasonably preparing Wushu modernization development evaluation indicator system, and grasping the main vein of the modernization development of Wushu [4].

Wushu modernization is a dynamic concept, and over hundreds of years in the modern development of China, the main features of the modernization development of Wushu is shown in the process of gradually developing the fighting technique and becoming a national traditional sport, and therefore the features of modernization development are mainly embodied as some features to be processed, mainly summarized as the following four aspects:

\section{A. Dynamization and relativization}

First of all, the modernization development of Wushu has features of dynamization and relativization. The modernization development of Wushu is a process of dynamization and relativization. "Modernization" is a dynamic process of development, but also a relative concept of development. Therefore, the modernization development of Wushu must not be separated from this internal law. The modern transformation of Wushu is not only a dynamic process of changing continuously, but also a process with stage development characteristics, and this stage development is an embodiment that the modernization development of Wushu has the features of relativization, and the modernization development of the next stage is embodied in comparison with status and main characteristics of performance of the previous stage. Thus, the modernization of Wushu has the characteristics of dynamic and 
relativity, and it is the basis of the modernization of Wushu, and it shows in the whole process of the modernization of Wushu. This process is not only reflected in the modern stage of development, but also in every stage and process of the modernization of Wushu. Therefore, "dynamic" and "relative" are two regular characteristics in the development of Wushu modernization.

\section{B. Socialization and internationalization}

The modernization development of Wushu is a process of internationalization and socialization, so the modernization development of Wushu has the characteristics of socialization and internationalization. The socialization development of Wushu is an important foundation of internationalization development, and the internationalization of Wushu is an important aspect of the socialization development of Wushu. In the development process, two of them are mutually integrated and influenced, promoted with each other.

Sport is a purposeful, conscious and organized social activity which people participate in, so as to enhance physical fitness, improve the technical level of sports, carry out the ideological and moral education, enrich the social and cultural lives in social development, through their participation in activities. In this process, as the main body of the society, people continue to advance their socialization by participating in sports. Wushu is a classical representative of national traditional sports in China and plays an important role in the mass fitness, and the development trend of the socialization cannot be halted, and such development of socialization may also continuously promote the industrialization and lifelization degree of Wushu, to achieve the sustainable development of Chinese Wushu.

Under the influence of the globalization of sports, the social development of Wushu is closely related to the internationalization development. Because the internationalization of modern sports is mainly manifested in the objective phenomenon of all-round development of sports in the global context, it does not only refer to the universality of development of sports, but also the long-term and lasting nature of sports. Therefore, the internationalization development of Wushu needs to combine the people with project well, and globalization development of Wushu has "good timing, geographical convenience and good human relations" from the internationalization popularity of the project itself development to the internationalization development organized by Wushu, then to the internationalization trend of Wushu personnel mobility. Thus, in the modernization development of Wushu, the internationality development features are particularly prominent, and to some extent reflect the level and extent of the modernization development of Wushu. Secondly, the feature of internationalization development of Wushu is not only an important feature of Wushu modernization, but also an important feature of modern social development. Therefore, Wushu embodies the development features of socialization and internationalization development in the modernization development, as well as the era requirement of the modern society for the future development of Wushu.

\section{Scientization and informatization}

Wushu is not only the development trend of scientization, informatization and so on in the modernization development, but also has development features of scientization and informatization, and it can be said that the scientization and informatization are two of the most remarkable features in the modernization development of Wushu. The modernization development of Wushu is also a process of scientization and informatization.

The continuous development of modern science and technology lays the foundation for the scientific development of Wushu. In 1980s, XIONG Douyin, a Chinese scholar, pointed out that modernization of sports mainly refers to a practice process to understand and solve problems in sports by means of the scientific thinking and advanced science and technology. In the development process of Chinese Wushu over recent decades, the scientization level continues to improve, not only reflected in the Wushu training, field and equipment, sports monitoring, sports science and technology, etc., but also embodied in the use of large-scale electronic information service system and so on, making Wushu become the direct object of modern science and technology applications, but also providing more channels for the public to better and more intuitively understand Wushu. For example, Wushu competitions and Wushu programs, television, webcast, and so on. It can be said that modern science and technology and Wushu promote each other and develop jointly, which has an important influence on the modernization development of the whole Wushu.

Informatization generally refers to a historical process which fully uses information technology, develops and utilizes information resources, and promotes information exchange and knowledge sharing, improves the quality of economic growth, and promotes the transformation of economic and social development. In modernization development, Wushu is deeply influenced by modern science and technology. It is possible to realize the informatization development of Wushu because of this far-reaching influence. The scientization development of Wushu provides the scientific support for the informatization development of Wushu, and therefore, the informatization and scientization developments of Wushu are homologous and are two sides of the development of the same thing, and reflect the features of the modernization development of Wushu from different aspects. In recent years, the informatization level of Wushu continues to develop in the modern development, not only reflected in the Wushu competition, in the scientific research, Wushu, but also embodied in fitness, sharing of Wushu resources, public entertainment etc.. Therefore, the scientization and informatization are very prominent features in the modernization development of Wushu.

\section{Diversification and humanization}

The modernization development of Wushu is characterized by diversification and humanization, and it is also a process of diversification and humanization at the same time. Wushu is one of the outstanding representatives of traditional culture of China, and its rich cultural deposits make it be the unique cultural essence of our country. With the continuous development of modern society, Wushu itself with the 
development in respect of all relevant aspects associated with it appears diversifying development trend, such as content and form of modern Wushu, field of development, mode of transmission and so on, which is no longer a single form, but also multipurpose in the form, rich and colorful. Moreover, this diversified development is not only embodied in the material and institutional aspects of Wushu, but also embodied in the spiritual level of Wushu, that is, the cultural connotation, mainly embodied in the humanistic spirit [5].

In the modern sense, the humanistic spirit mainly refers to the understanding and assurance of human existence and human dignity, value and significance, as well as the persistent pursuit of the value ideal or the ultimate ideal. With the continuous development of Wushu, Wushu has many attributes, such as sports and culture. Due to the great development focusing on the science and technology in modern society, it causes a certain degree of weakening or deficiency of humanistic spirit and traditional culture in the era. Therefore, Wushu is taken as the traditional sport, and its own cultural property and its rich cultural deposits are more and more obvious, more and more important, and Wushu is one of the best carriers in humanistic spirit and traditional culture in modern society. The cultural attribute of Wushu determines the uniqueness and inclusiveness of Wushu in the world sports arena. At the same time, with the constant diversification of humanistic spirit and values in modern society, the cultural connotation of Wushu is also constantly enriched and diversified, which makes the modernization of Wushu diversified and humanized. Thus, the modernization development of Wushu is a process of diversification and humanization. The development trends of the diversification and humanization of Wushu are complementary each other, jointly promoting the development of Wushu.

\section{CONCLUSION}

In the scope of sports development, the particularity of Wushu determines the particularity of Wushu development. Therefore, for the study of Wushu modernization, it is needed to be more rational and comprehensive, more thoroughly understand that the main contradictory relationship is the contradiction between nationality and internationality, contradiction between tradition and modernity, contradiction between cultural nature and physical nature; and the main features include dynamization and relativization, socialization and internationalization, scientization and informationization, diversification and humanization; it is hoped to provide theoretical references for the future development of Wushu.

\section{REFERENCES}

[1] XUE Yu, Study on the construction of Wushu modernization indicator system [D]. Master's Thesis of Beijing Sport University, 2010.

[2] Word-Ocean Dictionary [M], Shanghai Dictionary Press, 1999.

[3] XIAO Huanyu, WANG Shengli. Characteristics and the 21st century development tendency of modern sports $[\mathrm{J}]$. Journal of Shanghai University of Sport, 2001,259 (3): 9.

[4] HU Xiaoming. Opinion on Modernization of Chinese National Traditional Sports [J]. Journal of Wuhan Sports University, 2003 (7): 14.

[5] YU Xuehao, development and modernization of Chinese National Traditional Sports [J]. Journal of Physical Education, 2004 (5). 